\title{
ESTILOS DE APRENDIZAGEM: A REALIDADE DAS DIFERENÇAS INDIVIDUAIS EM SALA DE AULA
}

\author{
Marcia Boëchat FERNANDES \\ Karim Siebeneicher BRITO \\ Silvana POLCHLOPEK \\ Thaís Barbosa MAROCHI \\ Valéria de Fátima Carvalho Vaz BONI
}

\section{Resumo}

Este artigo relata as aplicações de um teste sobre preferências em estilos de aprendizagem em várias turmas de ensino de inglês como língua estrangeira. A análise dos dados revela uma forte relutância, por parte dos aprendizes, em desenvolver trabalhos em grupos, o que nos conduz à reflexão sobre a aparente contradição entre a teoria e a prática de sua aplicação.

Palavras-chave:: Estilos de aprendizagem; Interpessoal; Trabalhos em grupo.

\section{Introdução}

$\mathrm{Na}$ prática educacional contemporânea, especialmente quando se trata de língua estrangeira, o trabalho em pequenos grupos é considerado uma das atividades de sala de aula mais vantajosas para professores e alunos. Segundo essa perspectiva, e se cuidadosamente estruturado, esse tipo de atividade oferece a possibilidade de os alunos explorarem idéias e conceitos empregando padrões mais complexos e variados de linguagem, o que poderia gerar ganhos substanciais em termos de competência comunicativa.

Essas atividades normalmente exigem a manipulação de materiais, a exploração de questões e a busca pela solução de problemas, além da exposição a abordagens e pontos de vista alternativos. Nesse sentido, diversos autores (KINSELLA; e SHERAK (1995), McCAFFERTY, JACOBS e DaSILVA (2006), ARNOLD (1999) ) apontam o trabalho de grupo como uma atividade ideal para turmas heterogêneas, não 
somente por possibilitar ganhos quanto à aprendizagem cognitiva e habilidades interacionais, como também em relação a atitudes e relacionamentos entre os próprios alunos.

Segundo pesquisas (FIECHTNER e DAVIS(1992), GAYLE e MURPHY(1993), PICA(1994)) realizadas em diversos setores da área educacional, os alunos freqüentemente demonstram seu descontentamento frente a atividades dessa natureza devido a resquícios de um ensino tradicional, o qual pressupõe as atividades centradas exclusivamente na figura do professor e os alunos trabalhando individualmente. Outro aspecto considerado é o fato de que nem sempre as atividades em grupo são estruturadas como deveriam, isto é, prevendo uma participação ativa e equilibrada dos alunos ou a avaliação dos ganhos no desenvolvimento da linguagem e desempenho acadêmico. Portanto, não há como estabelecer expectativas que acarretem em sucesso, se os alunos são, muitas vezes, “jogados” nessas atividades em grupo, sem a devida preparação e/ou orientação.

A aparente falta de credibilidade desse tipo de atividade em língua estrangeira reside também no fato de que, muitas vezes, os alunos não têm um repertório pleno e adequado do idioma para interagir com os colegas, a saber: opinar, discordar, interromper, pedir para que uma idéia seja esclarecida, negociar. Em razão disso, lembramos o fato de que os estilos mais tradicionais de ensino, centrados na figura do professor, geralmente não prevêem atividades em grupo como uma metodologia aceitável e eficiente para a aprendizagem. Porém, se houver uma preocupação em desenvolver princípios instrucionais sólidos e objetivos e que considerem as diferenças individuais desses alunos, as chances de que essas atividades sejam melhor recebidas e conduzam, de fato, ao sucesso são maiores.

Em busca de soluções direcionadas para essa prática efetiva, é importante que o professor conheça os estilos de aprendizagem dos alunos e com base nesses dados possa elaborar as atividades práticas de modo que todos tenham a possibilidade de usar suas habilidades. Para tanto, descrevemos a seguir os estilos de aprendizagem mais comumente identificados em sala de aula. Na seqüência, apresentamos as pesquisas que realizamos em nossas salas de aula na tentativa de identificar os estilos de aprendizagem preferidos por nossos alunos, e a análise que fizemos dos dados levantados, bem como uma reflexão a respeito das implicações pedagógicas.

\section{Estilos de aprendizagem: teoria e prática}

FERNANDES, BRITO, POLCHLOPEK, MAROCHI \& BONI 
Um estilo de aprendizagem é uma maneira idiossincrática utilizada para desenvolver conhecimento, fundamentada no fato de que as pessoas aprendem de formas particulamente diferenciadas. Na Psicologia, a idéia de estilo foi apresentada formalmente por Allport (1937) (cf. STERNBERG e GRIGORENKO, 2001), referindo-se a ele como uma maneira de identificar tipos distintos de personalidade ou de comportamento. Essa compreensão sobre estilos baseava-se na teoria de Jung (cf. DICK, 1994) acerca dos tipos psicológicos.

Jung (1971) descreveu dois tipos genéricos que denominou introvertido e extrovertido. Os tipos gerais de atitude se distinguem por seu comportamento peculiar em relação ao objeto. O introvertido se comporta abstrativamente; está basicamente sempre preocupado em retirar a libido do objeto como a prevenir-se contra um superpoder do objeto. O extrovertido, ao contrário, comporta-se de modo positivo diante do objeto. Silveira (2007) comenta que cedo Jung deu-se conta de que dentro de cada uma das duas atitudes típicas havia muitas variações. Um introvertido podia diferir enormemente de outro, embora ambos reagissem de modo análogo face aos objetos. Idem se aplica no interior do grupo dos extrovertidos. Após várias observações empíricas, Jung concluiu que essas diferenças dependiam da função psíquica que o indivíduo usava preferentemente para adaptar-se ao mundo exterior. Sendo quatro essas funções de adaptação que a consciência usa para orientar-se: pensamento, sentimento, sensação e intuição.

Por outro lado, o termo “estilo” sofreu modificações ao longo dos anos, porém sua definição permanece a mesma: padrões habituais ou maneiras preferidas de se fazer algo, que permanecem consistentes ao longo do tempo e em diversas áreas de atividade. Características próprias dos indivíduos ajudam a determinar esses estilos, a saber: personalidade, preferências de interação social, o ambiente em que se dá a aprendizagem.

Conhecer como os nossos alunos preferem aprender pode auxiliar-nos na escolha e na condução das atividades em sala de aula, proporcionando uma aprendizagem mais prazerosa e eficaz. Essa noção justifica as pesquisas acerca dos estilos de aprendizagem, bem como as distinções entre eles, no sentido de serem indicadores das diferenças individuais e dos grupos de alunos com os quais trabalhamos. 
O conhecimento dos estilos preferidos pelos alunos permite uma preparação adequada dos materiais e dos recursos que serão utilizados no processo de ensino. Os avanços dos estudos nessa área têm sido expressivos, e sua importância já foi e continua sendo ressaltada em trabalhos acadêmicos. A intensidade de como cada pessoa aprende de forma diferente das outras é que determina que certos métodos instrucionais sejam mais efetivos para alguns do que para outros.

Para Felder e Silverman (1988), os estilos de aprendizagem refletem uma preferência característica e dominante na forma como as pessoas recebem e processam informações, considerando os estilos como habilidades passíveis de serem desenvolvidas e aperfeiçoadas. Isso significa que enquanto alguns alunos respondem preferencialmente a informações visuais, como figuras, diagramas e esquemas, outros respondem mais rapidamente a partir de informações verbais, orais ou escritas. Considerando, portanto, que as informações chegam até nós das mais diversas maneiras, é possível sermos mais eficientes se pudermos desenvolver nossos estilos particulares de lidar com essas informações. Nesse sentido, alguns estilos de aprendizagem podem ser apresentados da seguinte maneira (adaptação de Di Nizo, 2007, p. 31 - 32):

1. Físico (indivíduo que usa muito a expressão corporal)

2. Interpessoal (indivíduo extrovertido, prefere trabalhar com outros)

3. Intrapessoal (indivíduo introvertido, prefere a reflexão)

4. Lingüístico (aquele que se expressa melhor com palavras)

5. Matemático (o que apresenta maior capacidade de raciocínio lógico/matemático)

6. Musical (interessa-se mais por sons e música, pensa através do ritmo e da melodia)

7. Visual (explora mais o aspecto visual das coisas, preferindo trabalhar mais nessa dimensão)

Nesse contexto, este artigo centraliza-se na aplicação de um teste de preferências perceptuais de aprendizagem com vistas a identificar, em grupos de alunos distintos em sala de aula de ensino de inglês como língua estrangeira, os estilos de aprendizagem predominantes e comparar os resultados obtidos de forma a buscar alternativas que contemplem de alguma maneira a heterogeneidade dos grupos em relação a esses estilos.

\section{Descrição do teste}


O teste foi selecionado do livro Learning Styles in the ESL/EFL Classroom, organizado por Reid (1995), que como apêndice 3, do Capítulo 2, apresenta o questionário “Preferências Perceptuais em Estilos de Aprendizagem”, (tradução nossa) com 30 perguntas (cf. anexo) a serem respondidas seguindo os seguintes parâmetros: “concordo plenamente; concordo; não tenho certeza; discordo e discordo totalmente”, cada um com uma pontuação específica. Uma segunda parte prevê que os alunos somem essa pontuação de acordo com um grupo de perguntas que corresponde a cada um dos estilos de aprendizagem, por exemplo: para o estilo "Visual” o aluno deve somar os pontos correspondentes às perguntas 6, 10, 12, 24 e 29 (ver anexo).

Os resultados deste questionário são divididos em três tipos de preferências, apresentadas como principais, menores e indiferentes. As preferências principais são consideradas dominantes. As preferências menores entre os estilos indicam, segundo Reid, áreas em que o aprendiz pode operar bem, se praticar e buscar aperfeiçoá-las. Já as preferências chamadas indiferentes, conforme Reid, indicam dificuldade em aprender dessa maneira. Dificilmente os alunos direcionam sua aprendizagem a esses estilos.

\section{Aplicação do teste}

As pesquisas foram desenvolvidas pelas autoras a princípio individualmente, visando identificar os estilos de aprendizagem predominantes entre os seus aprendizes adolescentes e/ou adultos de Inglês como língua estrangeira, a fim de que suas preferências pudessem ser discutidas em classe e contempladas nas atividades. Tínhamos como objetivos aprofundar os conhecimentos pessoais sobre os estilos de aprendizagem, e observar como aprendizes de Inglês como língua estrangeira respondem quando questionados acerca de suas próprias preferências. Após a discussão dos resultados, perceberam-se algumas semelhanças interessantes. Agrupamos, então, os dados de todas as turmas para analisá-los conjuntamente, o que nos propomos a apresentar e discutir neste artigo. São apresentados também os resultados gerais individuais, nos gráficos que seguem os dados de cada pesquisa individual.

$1^{\circ}$ grupo - Professora Karim Siebeneicher Brito

O questionário foi aplicado a cinco (5) alunas. Duas delas têm 13 anos de idade, freqüentam as aulas duas vezes por semana totalizando três horas, e encontram-se 
no nível elementary. As outras três têm 15 anos, freqüentam as aulas uma vez por semana totalizando duas horas, e encontram-se no nível intermediate.

As aprendizes receberam os questionários escritos em língua portuguesa, sua língua nativa (cf. anexo), e foram instruídas a lê-los e respondê-los pensando em suas preferências quanto à aprendizagem de Inglês.

Conforme o gráfico abaixo, observou-se que as preferências mais destacadas pelas aprendizes referem-se aos estilos individual, visual e tátil, enquanto que o único estilo apontado como indiferente, ou aquele em que não gostam de desenvolver suas atividades, foi o grupal.

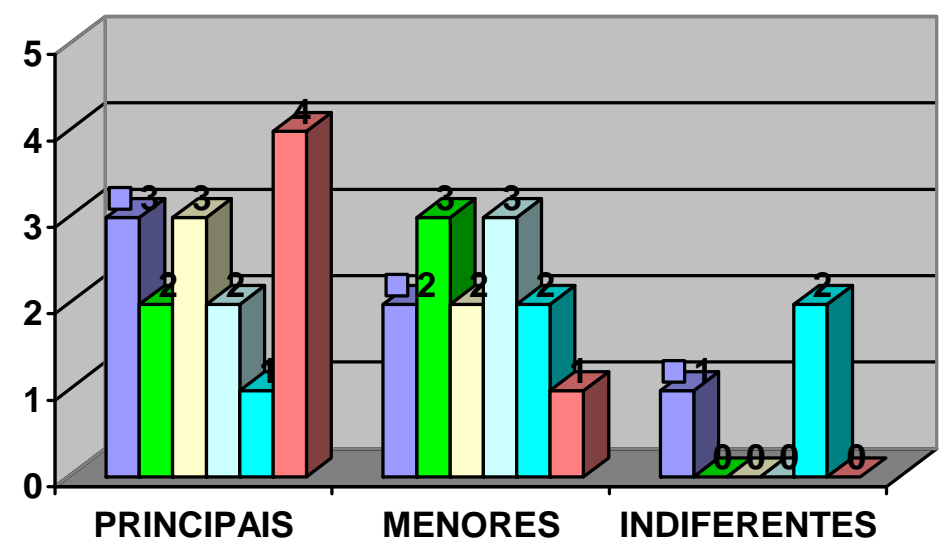

\begin{tabular}{|l|}
\hline$\square$ Visual \\
$\square$ Auditivo \\
$\square$ Tátil \\
$\square$ Cinestésico \\
$\square$ Grupal \\
$\square$ Individual \\
\hline
\end{tabular}

\section{$2^{\circ}$ grupo - Professora Silvana Polchlopek}

Neste caso, o teste foi aplicado para um total de dezenove (19) respondentes, sendo 12 alunos do curso de Inglês Instrumental e sete do curso de Turismo, da Universidade Federal do Paraná.

O perfil dos alunos de Inglês Instrumental é bastante diversificado, visto que são de cursos diversos. Exceto por alguns grupos pequenos de alunos de um mesmo curso que se formam na disciplina, os outros dificilmente interagem no ambiente de sala. Esses alunos cursam a disciplina por várias razões, a saber: preencher a carga horária; ser aprovado na prova de suficiência em língua estrangeira (mestrado e doutorado); manter ativo o contato com a língua; interesse em ler artigos no original em inglês ou ainda porque desejam conhecer a língua. Já os alunos de Turismo entrevistados para este artigo cursavam o último semestre do curso pelas mesmas razões mencionadas acima e também por não terem sido aprovados ou terem perdido o teste de 
adiantamento. Esse fato acarreta não só a obrigação de cursar a disciplina para poder se formar como também um embate com a realização dos trabalhos de conclusão de curso (TCCs) que devem ser realizados e defendidos na mesma época, implicando uma quase ausência de motivação intrínseca, ainda que a aula fosse voltada inteiramente ao universo do curso.

Por fim, ressaltamos a heterogeneidade no que diz respeito ao conhecimento e domínio do idioma em ambas as turmas. Há casos, num mesmo grupo, em que os alunos não conhecem nada a respeito do idioma, enquanto outros o dominam por completo.

1 - Turma de Inglês Instrumental

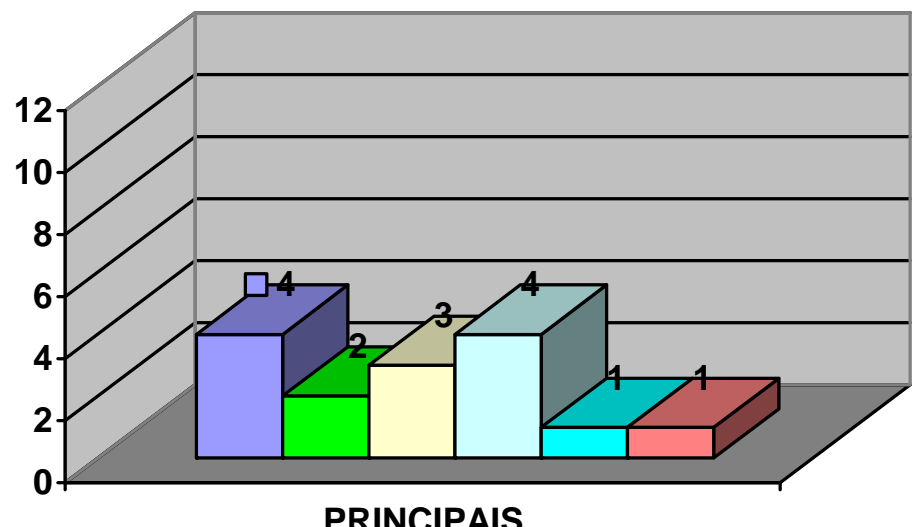

\begin{tabular}{|l|}
\hline$\square$ Visual \\
$\square$ Auditivo \\
$\square$ Tátil \\
$\square$ Cinestésico \\
$\square$ Grupal \\
$\square$ Individual \\
\hline
\end{tabular}

2 - Turma de Turismo 


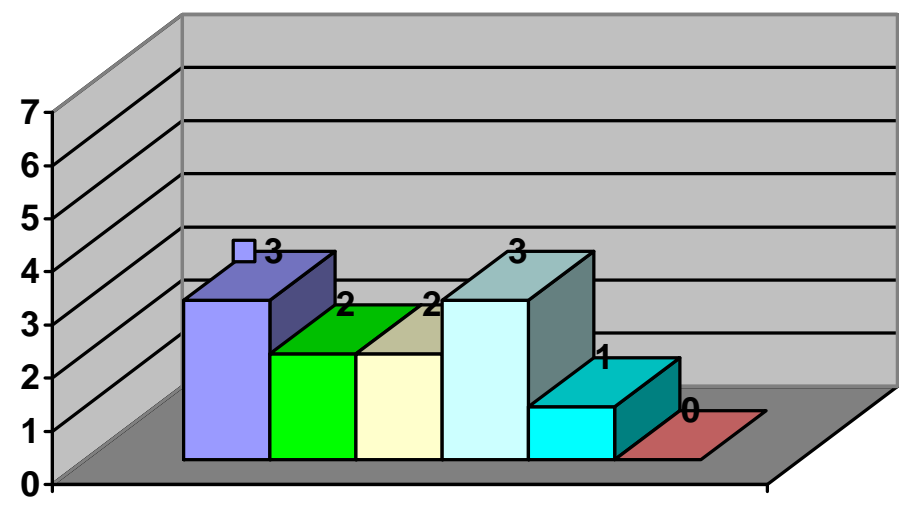

\begin{tabular}{|l|}
\hline$\square$ Visual \\
$\square$ Auditivo \\
$\square$ Tátil \\
$\square$ Cinestésico \\
$\square$ Grupal \\
$\square$ Individual \\
\hline
\end{tabular}

PRINCIPAIS

$3^{\circ}$ grupo - Professora Valéria de Fátima Carvalho Vaz Boni

Aplicou-se o questionário a doze (12) estudantes de duas turmas do Curso de Letras Português / Inglês da FAFIUV - Faculdade Estadual de Filosofia, Ciências e Letras de União da Vitória, no Estado do Paraná, sendo elas a primeira e a terceira séries do Curso.

Apresentamos abaixo o gráfico que demonstra as preferências individuais apontadas pelos estudantes da primeira série.

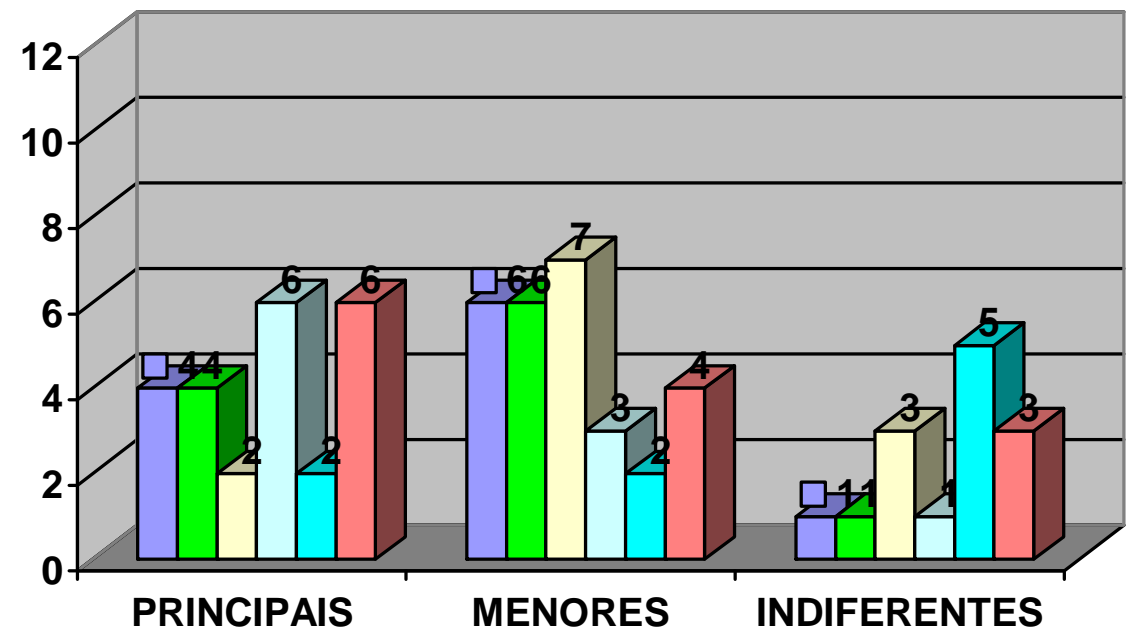

\begin{tabular}{|l|}
\hline$\square$ Visual \\
$\square$ Auditivo \\
$\square$ Tátil \\
$\square$ Cinestésico \\
$\square$ Grupal \\
$\square$ Individual \\
\hline
\end{tabular}

A aparente distorção entre o número de respondentes e a totalização dos dados deve-se ao fato de que muitos aprendizes escolheram mais de uma alternativa simultaneamente. 
Da leitura dos gráficos depreende-se que, com relação aos estilos principais, os estudantes apontam, principalmente, o cinestésico e o individual, ou seja, apreciam atividades de aprendizagem que envolvam movimento físico, e também aquelas nas quais trabalham individualmente.

Entre os estilos disponíveis, foram apontados como menores, principalmente o tátil, o visual e o auditivo. Isto significa que dessas três maneiras os estudantes aceitam desenvolver atividades, embora não sejam suas preferências principais.

Indicados como estilos indiferentes principalmente o grupal, o tátil e o individual, sendo que o grupal bastante acima de todos os outros. Isto indica que a maneira pela qual os estudantes menos preferem estudar é em grupos.

\section{$4^{\circ}$ grupo - Professora Thaís Barbosa Marochi}

Participaram desta pesquisa dezessete (17) alunos, sendo 5 homens e 12 mulheres, todos alunos do $4^{\circ}$ período do curso noturno de Letras da Faculdade Educacional de Araucária - FACEAR, localizada na região metropolitana de Curitiba, estado do Paraná.

Os alunos têm duas aulas semanais de língua estrangeira (Inglês) que, no momento, são ministradas por outra professora. Mas, como as duas disciplinas trabalhadas pela pesquisadora (Estágio Supervisionado I e Cultura Anglo-Americana) possibilitam o uso de língua estrangeira (Inglês) em sala de aula, pode-se observar também a heterogeneidade da classe. Duas alunas já lecionam Inglês em escolas de nível fundamental e uma outra concluiu o nível intermediário de Inglês em um curso particular de línguas. Além disso, há alunos que já estudaram o idioma anteriormente em escolas de línguas, outros que estudaram apenas no Ensino Médio e outros que estudaram apenas durante o curso de Letras.

Apresentamos a seguir o gráfico que representa os resultados gerais desta pesquisa, no qual identificamos a preferência, por parte dos aprendizes, dos estilos auditivo e cinestésico. Diferentemente dos resultados dos outros grupos, no entanto, estes aprendizes apontaram o estilo individual como aquele ao qual mais são indiferentes, ou resistentes. 


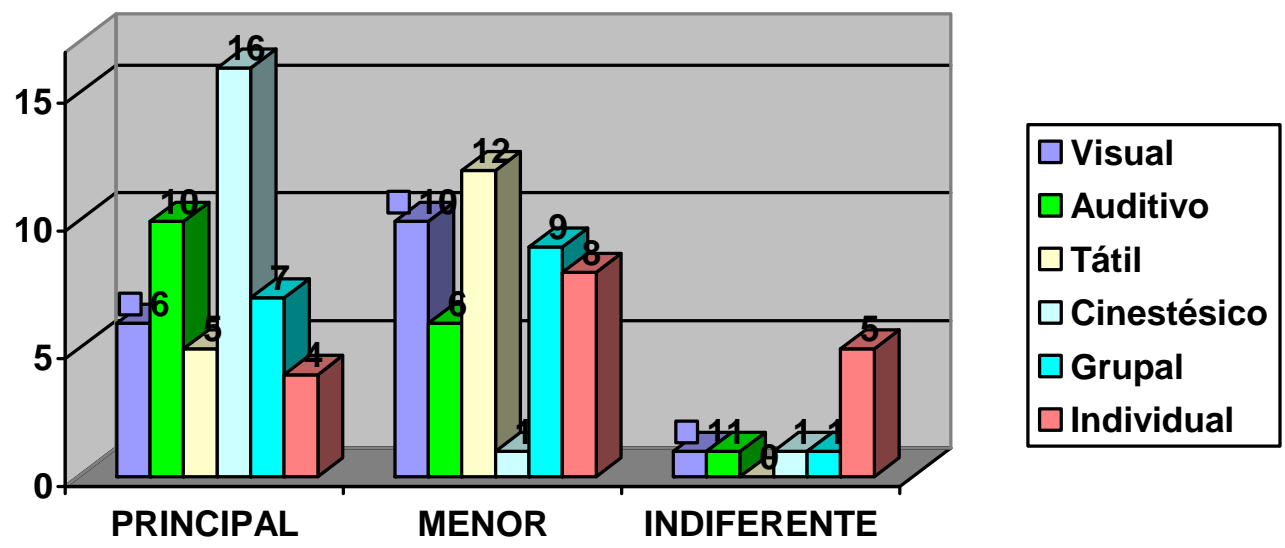

\section{Análise e discussão dos resultados}

Um total de cinqüenta e três (53) questionários foi analisado pelas professoras dos respondentes. Em discussão posterior às aplicações pelas autoras, pudemos perceber algumas semelhanças significativas referentes a alguns resultados, o que indica que ocorrem certas predominâncias de preferências. Apesar de terem sido instruídos para responderem aos questionários considerando suas preferências referentes à aprendizagem de língua inglesa, durante conversa posterior os aprendizes revelaram terem tido dificuldade em fazer a distinção entre as aulas de língua inglesa e as outras aulas que têm em suas situações de ensino regular, enquanto pensavam nas respostas. Elas refletem, portanto, não apenas suas a forma como preferem aprender a língua estrangeira, mas em muitos casos também como escolheriam aprender qualquer outra disciplina em sala de aula.

De modo geral, os estilos dominantes foram: individual, visual e cinestésico. Os diálogos com os alunos, posteriores às aplicações do teste, confirmaram suas preferências nesse sentido. Porém o aspecto que mais se destacou, por ter sido identificado em quase todos os grupos aos quais se aplicou o teste, foi a aversão que os alunos demonstraram por atividades em grupos. O estilo chamado grupal não só não configurou entre os bem aceitos pelos alunos, mas também foi apontado como indesejável.

Kinsella e Sherak (1995) alertam para as experiências desapontadoras que os aprendizes trazem consigo, que os levam a considerar as atividades em grupos como improdutivas e, por vezes, desagradáveis. Tais impressões devem-se, conforme as 
autoras, ao fato de que sua experiência em sala de aula inclui pouco envolvimento em atividades em grupos de forma consistente e contínua, e também às suas experiências pessoais de terem sido bem-sucedidos na aprendizagem trabalhando individualmente. A fim de evitar tantas impressões contrárias ao desenvolvimento de atividades em grupos na sala de aula, Kinsella e Sherak (op. cit., p. 93) listam alguns princípios a serem seguidos, e desta forma garantir que os aprendizes sejam beneficiados por sua participação nessas atividades. Os princípios incluem, por exemplo, a estruturação das atividades, em que fiquem claros seus objetivos, seus procedimentos e seus resultados; a variação dos tipos de atividades; a discussão posterior ao desenvolvimento da atividade, para que se esclareça o que foi desenvolvido; a ação facilitadora e de suporte exercida pelo professor.

Uma hipótese que levantamos para explicar esse resultado é que elas não são resistentes à utilização de estilos variados, a despeito de suas preferências principais; resguardam-se, porém, com relação ao trabalho em grupos, pois têm visto nele muito mais aspectos negativos do que positivos.

\section{Conclusão}

Vivemos hoje em um mundo de muitas mudanças ocorrendo em uma velocidade crescente. Neste contexto, nossas vidas profissional e pessoal dependem mais e mais de nossa capacidade de adaptação ao mundo exterior. Por isso, nossos objetivos de aprendizagem devem incluir sermos eficientes aprendizes ao longo da vida. E só conseguiremos isto se nos dedicarmos a compreender como aprendemos e como podemos melhorar nosso desempenho como aprendizes. Conhecer nossos próprios processos de aprendizagem e aprender como aprender devem ser nossas principais armas para conseguirmos a flexibilidade necessária a essa nova realidade, porém o caminho para atingirmos este objetivo é tão individual quanto o processo de aprendizagem em si. As pessoas têm estilos diferentes de aprendizagem. Não há uma pessoa igual à outra. As preferências de cada aprendiz não são exatamente as mesmas, mas isto não quer dizer que são melhores ou piores.

Por fim, os professores devem alargar sua visão educacional, para dimensões mais profundas da vida psíquica do aprendiz, criando práticas de estudo independente que incentivem a sua autonomia intelectual. Neste sentido, o professor deve escolher criteriosamente diferentes abordagens contextualizadas histórica, social e FERNANDES, BRITO, POLCHLOPEK, MAROCHI \& BONI 
politicamente,através do desenvolvimento de atividades realistas que possam transportar à reflexão sobre o mundo exterior contemporâneo, contribuindo a formação de um cidadão ativo dentro de todas as esferas públicas.

\section{Referências}

ARNOLD, J. (Ed.) Affect in language learning. Cambridge, UK: Cambridge University Press, 1999.

DI NIZO, R. A educação do querer: ferramentas para o autoconhecimento e a auto-expressão. São Paulo: Ágora, 2007.

DICK, B. Jung for skeptics: Jung's psychological types as decision-making preferences. Chapel Hill, Australia: Interchange publications, 1994.

FELDER, R. M.; SILVERMAN, L. K. Learning and teaching styles in engineering education. Engineering Education, 78(7), p. 674 - 681, 1988.

FIECHTNER, S,; DAVIS, E. Why some groups fail: a survey of students' experiences with learning groups. In GOODSELL, M. M.; TINTO, V. (Eds.) Collaborative learning: a sourcebook for higher education. University Park: Pennsylvania State University, National Center on Postsecondary Teaching, Learning and Assessment, 1992.

GAYLE, N L.; MURPHY, J. M. Peer response groups: do L2 writers use peer comments in revising their drafts? TESOL Quarterly 27, n. 1, 1993, p. 135 - 141.

JUNG, C. G. Tipos Psicológicos. Petrópolis. Editora Vozes, 1991.

KINSELLA, K.; SHERAK, K. Designing ESL classroom collaboration to accommodate diverse work styles. In: REID, J. (Org.) Learning styles in the ESL/EFL classroom. Boston, MA: Heinle and Heinle Publishers, 1995, p. 85 - 99. 
McCAFFERTY, S. G; JACOBS, G M.; IDDINGS, A. C da S. (Eds.) Cooperative learning and second language teaching. New York: Cambridge University Press, 200.

PICA, T. Research on negotiation: what does it reveal about second-language learning conditions, processes, and outcomes? Language Learning 44(3), 1994, p. 493 - 527.

REID, J. (Org.) Learning styles in the ESL/EFL classroom. Boston, MA: Heinle and Heinle Publishers, 1995.

SILVEIRA, N. Jung :Vida e Obra. Rio de Janeiro: Coleção Vida e Obra, 2007.

STERNBERG, R. J.;GRIGORENKO, E. L. A capsule history of theory and research on styles. In: STERNBERG, R J.; ZHANG, L. (Ed.) Perspectives on thinking, learning, and cognitive styles. Mahwah, NJ: Lawrence Erlbaum Associates, 2001. 


\title{
ANEXO \\ Levantamento das Preferências Perceptuais em Estilos de Aprendizagem
}

\author{
Joy Reid
}

Instruções: As pessoas aprendem de muitas maneiras diferentes. Por exemplo, algumas pessoas aprendem principalmente com seus olhos (aprendizes visuais) ou com seus ouvidos (aprendizes auditivos); algumas pessoas preferem aprender pela experiência e/ou através de tarefas “com a mão na massa” (aprendizes cinestésicos ou táteis); algumas pessoas aprendem melhor quando trabalham sozinhas, e outras preferem aprender em grupos. Este questionário foi desenvolvido para ajudá-lo a identificar a(s) maneira(s) pelas quais você aprende melhor - a(s) maneira(s) pelas quais você prefere aprender.

Leia cada afirmação nas páginas seguintes. Por favor marque as suas opções conforme elas se aplicam ao seu estudo de inglês. Decida se você concorda ou discorda de cada afirmação. Por exemplo, se você concorda plenamente (CP), marque:

\begin{tabular}{|lrr|r|}
\hline $\begin{array}{l}\text { Concordo plenamente } \\
\text { totalmente }\end{array} \quad$ Concordo & Não tenho certeza & Discordo & Discordo \\
$(\mathrm{CP})$ & $(\mathrm{C})$ & $(\mathrm{NC})$ & \\
\hline $\mathrm{X}$ & & & \\
\hline
\end{tabular}

Após ler cada afirmação, marque sua opção rapidamente, sem pensar durante muito tempo. Tente não mudar suas respostas depois de tê-las escolhido. Por favor marque todas as questões. Depois utilize os materiais que seguem o questionário para avaliar suas respostas.

\section{CP C NC D DT}

1. Quando a professora me diz as instruções, eu 


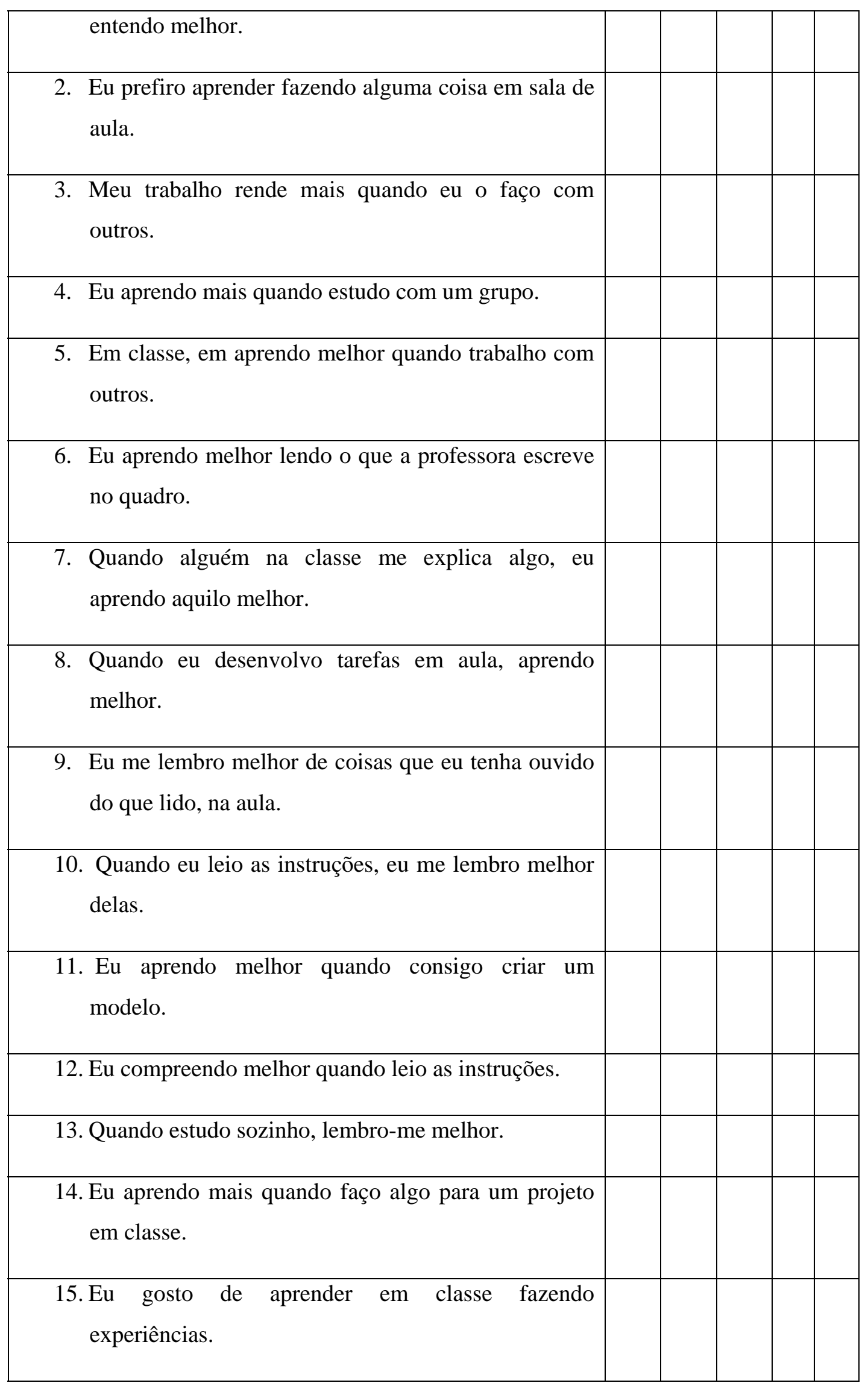




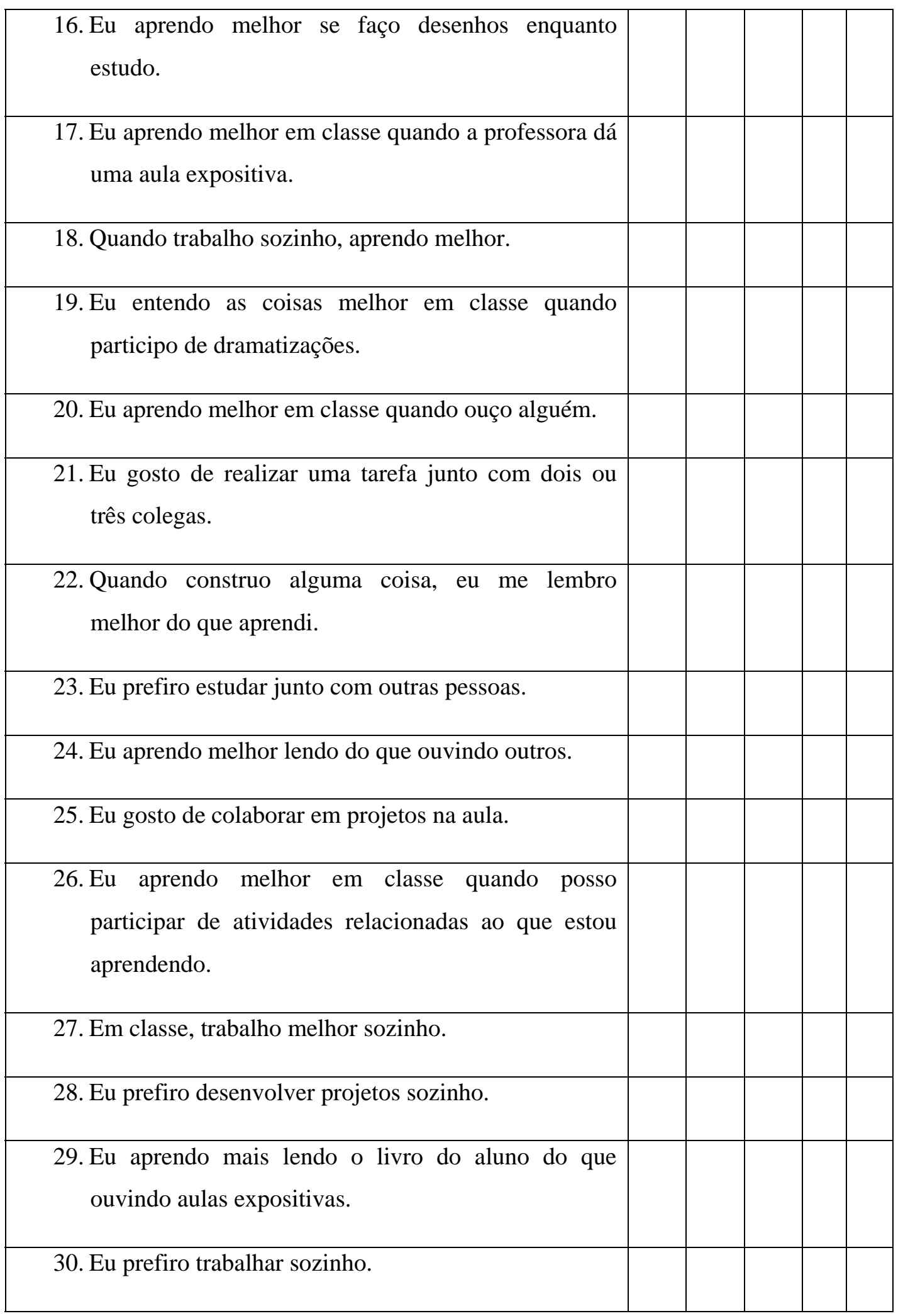


Folha de auto-avaliação para o Levantamento de Preferências Perceptuais em Estilos de Aprendizagem

Instruções: Há cinco afirmações para cada categoria de aprendizagem neste questionário. As questões estão agrupadas abaixo de acordo com cada estilo de aprendizagem. Cada questão que você responde recebe um valor numérico:

\begin{tabular}{|c|c|c|c|c|}
\hline $\begin{array}{c}\text { Concordo } \\
\text { Plenamente } \\
\text { (CP) }\end{array}$ & $\begin{array}{c}\text { Concordo } \\
\text { (C) }\end{array}$ & $\begin{array}{c}\text { Não Tenho } \\
\text { Certeza } \\
\text { (NC) }\end{array}$ & $\begin{array}{c}\text { Discordo } \\
\text { (D) }\end{array}$ & $\begin{array}{c}\text { Discordo } \\
\text { Totalmente } \\
\text { (DT) }\end{array}$ \\
\hline $\mathbf{5}$ & $\mathbf{4}$ & $\mathbf{3}$ & $\mathbf{2}$ & $\mathbf{1}$ \\
\hline
\end{tabular}

Preencha as lacunas abaixo com o valor numérico de cada resposta. Por exemplo, se você marcou Concordo Plenamente para a afirmação 6 (uma questão visual), escreva o número 5 (CP) na lacuna ao lado da questão 6.

Visual

$$
6-\underline{5}
$$

Quando tiver completado todos os valores numéricos para o aspecto Visual, some os números. Multiplique o resultado por 2, e escreva o total na lacuna apropriada.

Siga esse processo para cada uma das categorias de estilos de aprendizagem. Quando terminar, consulte a escala que segue. Ela a ajudará a determinar sua(s):

Preferência(s) principal(is) em estilos de aprendizagem: escore: 38-50

Preferência(s) menor(es) em estilos de aprendizagem: escore: 25-37

Preferência(s) indiferente(s) em estilos de aprendizagem: escore: 0-24

Se precisar de ajuda, peça à professora.

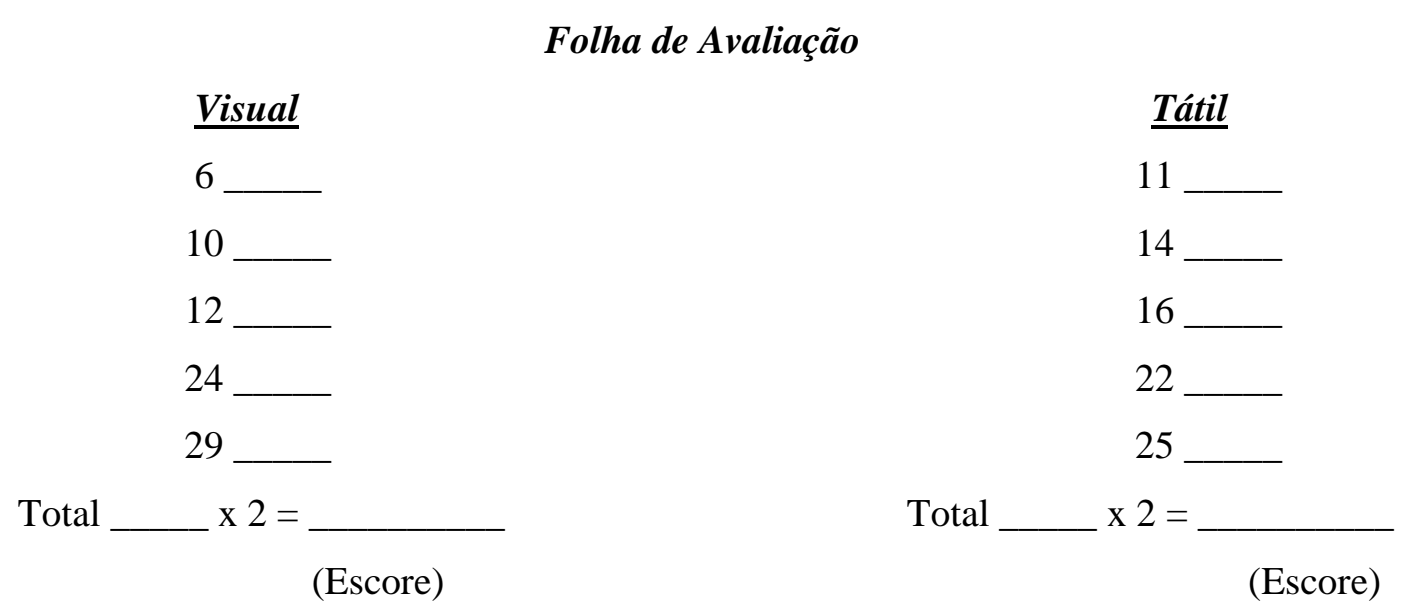




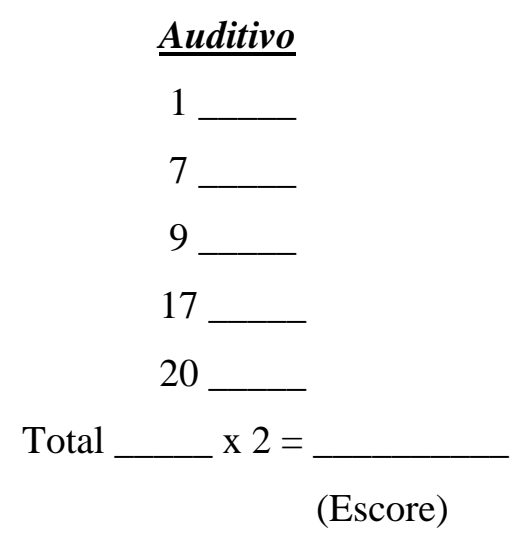

\section{Cinestésico}

2

8

15

19

26

Total $\times 2=$

\section{Grupal}

3

4

5

21

23

Total $\mathrm{x} 2=$

\section{Individual}

13

18

27

28

30

Total $\mathrm{x} 2=$

(Escore)

\section{Explicação das Preferências Perceptuais em Estilos de Aprendizagem*1}

Os alunos aprendem de muitas maneiras diferentes. Os resultados do Questionário de Preferências Perceptuais em Estilos de Aprendizagem mostra de que maneiras você prefere aprender Inglês. Em muitos casos, as preferências em estilos de aprendizagem dos alunos demonstram quão bem eles aprendem a matéria em diferentes situações.

As explicações das preferências principais em estilos de aprendizagem abaixo descrevem as características desses alunos. As descrições lhe fornecerão informações sobre as maneiras pelas quais você aprende melhor.

Preferência principal Visual em estilos de aprendizagem

Você aprende melhor vendo as palavras em livros, no quadro, e em livros de exercícios. Você lembra e compreende informações e instruções melhor se você as ler. Você não precisa de tanta explicação oral como um aprendiz auditivo, e você consegue muitas

\footnotetext{
${ }^{1}$ A explicação dos estilos de aprendizagem foi adaptada do Instrumento de Estilos de Aprendizagem C.I.T.E., do Centro de Ensino Murdoch, Wichita, Kansas 67208. Utilizado com permissão.
} 
vezes aprender sozinha com o livro. Você deve tomar notas de aulas expositivas, palestras e instruções orais, se quiser se lembrar das informações.

Preferência principal Auditiva em estilos de aprendizagem

Você aprende ouvindo as palavras faladas e através de explicações orais. Você pode se lembrar de informações lendo-as em voz alta, ou movendo seus lábios enquanto lê, especialmente quando está estudando matéria nova. Você se beneficia de ouvir gravações, palestras, e discussões em classe. Você também se beneficia de produzir gravações para ouvi-las depois, de ensinar para os colegas, e de conversar com sua professora.

Preferência principal Cinestésica em estilos de aprendizagem

Você aprende melhor pela experiência, envolvendo-se fisicamente nas experiências de sala de aula. Você se lembra bem de informações quando participa ativamente de atividades, aulas de campo, e de dramatizações durante a aula. Combinações de estímulos - por exemplo, uma gravação em áudio juntamente com uma atividade ajudarão você a compreender matéria nova.

Preferência principal Tátil em estilos de aprendizagem

Você aprende melhor quando tem a oportunidade de participar experiências nas quais “põe as mãos” nos materiais. Ou seja, fazer experiências num laboratório, manusear e construir modelos, tocar e trabalhar com materiais lhe fornecem as situações de aprendizagem em que você é mais bem-sucedida. Fazer anotações ou escrever instruções pode ajudá-la a se lembrar de informações, e o envolvimento físico nas atividades escolares podem ajudá-la a compreender matéria nova.

Preferência principal Grupal em estilos de aprendizagem

Você aprende mais facilmente quando estuda com pelo menos mais uma aluna, e você será mais bem-sucedida nos exercícios quando trabalhar com outros. Você valoriza a integração com o grupo e o trabalho em aula com as colegas, e você se lembra melhor das informações quando trabalha com duas ou três colegas. O estímulo que você recebe do trabalho em grupo a ajuda a aprender e compreender novas informações.

Preferência principal Individual em estilos de aprendizagem 
Você aprende melhor quando trabalha sozinha. Você pensa melhor quando estuda sozinha, e você se lembra das informações que aprende sozinha. Você entende melhor a matéria quando a aprende sozinha, e progride mais na aprendizagem quando trabalha sozinha.

\section{Estilos de aprendizagem menores}

Na maioria dos casos, os estilos de aprendizagem chamados menores indicam áreas em que você pode operar bem como aprendiz. Geralmente, um aprendiz muito bemsucedido consegue aprender de várias maneiras diferentes, e portanto talvez você queira experimentar formas de praticar e aperfeiçoar seus estilos de aprendizagem menores.

\section{Estilos de aprendizagem indiferentes}

Com freqüência, um escore indiferente indica que você pode ter dificuldade em aprender daquela maneira. Uma solução pode ser direcionar sua aprendizagem aos seus estilos mais dominantes. Outra solução pode ser tentar desenvolver algumas das habilidades que podem aperfeiçoar seu(s) estilo(s) de aprendizagem em áreas indiferentes. 